\title{
Power Quality Enhancement of Grid Integrated Distribution System with Renewable Energy Sources
}

\author{
K Lokeswara Rao ${ }^{1}$, SLV Sravan Kumar ${ }^{2}$ \\ ${ }^{1}$ Assistant Professor, EEE Dept, GITAM School of Technology, KA, India. lokeshch85@gmil.com \\ ${ }^{2}$ Assistant Professor, EEE Dept, ALIET, Vijayawada, AP, India. sravan_257@yahoo.co.in
}

\begin{abstract}
Nowadays, Renewable Energy Sources (RES) integration to Distribution Systems (DS) by employing latest Power Electronic Converters (PEC) is highly increased. This paper presents, a new grid connected / interfacing inverter control organization for a 3- $\varnothing 4$-wire DS. The implemented inverter is incorporated with Active Power Filter (APF) functionality which can control and perform as a multi-functional device. So, the inverter is operated as both power converter and Shunt APF as well. The power converter function is to inject the real power into the grid, whereas the shunt APF is to minimize reactive power demand, current harmonics and unbalance current. With the effective inverter control scheme, the 3-phase 4-wire DS at PCC seems as balanced load to grid. The inverter and its control scheme are implemented in using MATLAB /Simulink environment.
\end{abstract}

Key words : APF; Voltage Source Inverter; Power Quality; RES..

\section{INTRODUCTION}

The anonymous increase of electrical demand in the modern civilization, researchers are searching towards the clean energy development without effecting the environment. In this aspect, the RES are the most promising alternatives to others. On the other hand, it is not viable to carry bulk amount of power from remote stations to load centers. Then there is an evolution of the term Distributed Generation (DG) which means generation at load centers [1],[2]. The RES are intermittent in nature, whereas the load on the system is not constant. So, to integrate RES in to the existing grid sophisticated control strategies are required.

In the modern power system, power generation units are suffered from two limitations such as lack of fossil fuel and carbon emission. Moreover, an electrical power loss due to transmission lines is another constraint. So these consequences driving fossil fuel based power generation units to DG with RES in to the grid. This results in efficient energy, reduced power losses and emissions. Integration RES to the medium to low voltage power transmission system is becoming good research platform. Almost, the integration of
RES could be done with PECs. While integrating DG to the grid and to meet the power quality standards, mainly power electronic converters is used. Exponential growth is with DGs such as grid connected systems with number of PV and wind installations. Besides them, the main drawbacks of the systems are low efficiency and controllability, if none controlled properly, lead to grid collapse. The integration of RES is a reason of power quality issues to the grid. Many studies and researches have already noticed the impact of RES penetration on the distribution system [3],[4]. A simple reason behind unfavorable effects on the grid is, leaving the DG on its own. It requires proper counteracting solutions and superior control schemes.

The paper sections are arranged as follows: The section II defines the several grid interfacing technologies available to integrate DG. Section III explains about the architecture of the proposed system. The main importance of DC link between the RES and inverter with the help of mathematical equations is explained in Section IV. Section V presents the proposed control scheme with PI \& Hysteresis current controller. Sections VI concentrates on the simulation results.

\section{DIFFERENT TYPESOF GRID INTERFACES}

As per the grid codes, the RES based generators are not directly integrated to the grid. It requires medium voltage level conversion/transmission media in between RES generators and grid. In case of solar PV panels, a dc-to-ac converter is necessary to integrate the grid. Subsequently, in case of small hydro or wind generators can be directly integrated to the grid which creates low conversion efficiency, poor power quality and starting transients. Therefore, PECs are requiring as a best choice for integrating variable RES. Table 1 describes about the RES types of generations and their preferred interfacing technology to grid [5].

Table 1 Types of generations and their preferred interfacing

\begin{tabular}{|l|l|}
\hline $\begin{array}{l}\text { Type } \\
\text { Interfacing }\end{array}$ & Technology \\
\hline Photovoltaic & PECs \\
\hline Wind & Induction generator/ PECs \\
\hline Small hydro & $\begin{array}{l}\text { Induction or synchronous } \\
\text { generator, PECs }\end{array}$ \\
\hline Fuel cells & PECs \\
\hline
\end{tabular}


K Lokeswara Rao et al., International Journal of Emerging Trends in Engineering Research, 8(8), August 2020, 4607 - 4612

Mostly, current controlled VSIs are utilized to integrate RES in DS. Nevertheless, the wide-ranging use of PECs and unbalanced loads at PCC may deteriorate the power quality. Nowadays, the p-q theory based grid integrated inverters are proposing with several control strategies. To absorb the harmonic current, at a certain frequency the inverter operates as active inductor. Nevertheless, in real time, obtaining the network inductance is difficult which may deteriorate performance of a controller. So, to overcome such situation, shunt APF is proposed to damp out the harmonics in DS, because it acts as active conductance. Finally, p-q theory based strategy is proposed for grid integrated inverter. To minimize the current harmonics of the load, load and inverter current sensing is necessary for the control strategy. In this strategy, the control scheme employs Fuzzy Logic Controller (FLC) which has more advantages [6].

\section{SYSTEM DISCRIPTION}

The schematic representation of proposed RES based DG system is shown in Figure 1, which mainly comprises of RES, DC-link, 4-leg grid interfacing inverter, hysteresis controller and a distribution grid. The VSI is a main interface in between the RES and grid. The RES is a DC/AC source depending on the energy source (solar or wind). However, a rectifier is coupled with DC-link. In general, variable speed wind generators produce variable AC voltage, whereas photovoltaic and fuel cell generates variable low DC voltage. Therefore, to connect a RES with DC link a power conditioning devices (ac/dc or dc/dc converters) are essential. The DC-link divides RES and grid which gives advantages such as no fault transfer and independent control of converters [7].

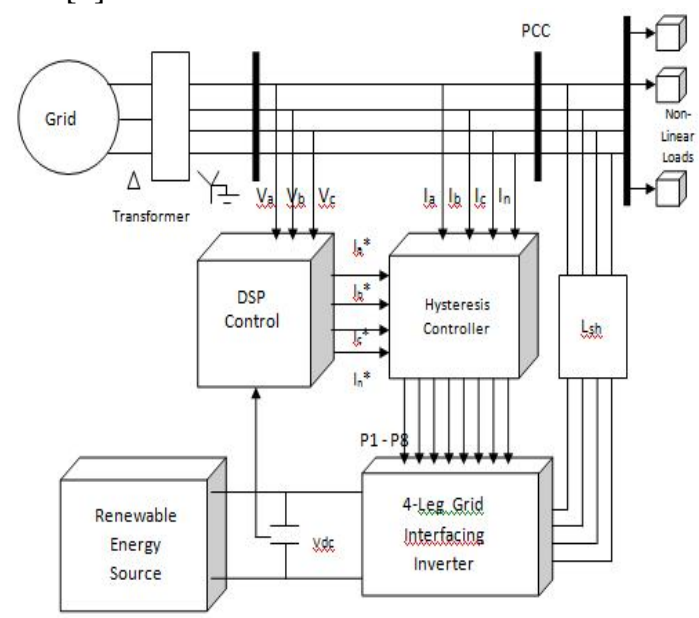

Figure 1: Schematic representation of RES based DG system

\section{CONTROL OPERATION OF DC-LINK VOLTAGE AND POWER}

The power generated by RES is not constant due to their intermittent nature. For integration of renewables in to grid for power transfer DC link plays a main role. While, implementing the DC link the RES is treated as current source connected to the DC side of the inverter. The basic connection of RES to grid is depicted in Figure 2. The current source is an equivalent value of RES current generation, if the RES is an photovoltaic system the output current depends on and temperature of the solar radiation. Since, the output power is DC, no need of extra converter for conversion. If the connected DG source is a wind turbine the power from the alternator is an alternating quantity [8]. This AC must be converted in to equivalent $\mathrm{DC}$ power by means of a converter, for mathematical analysis in terms of DC. It contains current source equivalent of RES and DC link capacitor. The Eqn. (1) represents the current injected from RES to DC link at voltage $\mathrm{V}_{\mathrm{dc}}$.

$I_{\text {de1 }}=\frac{P_{h \mathrm{heS}}}{V_{\text {dit }}}$

where, $P_{R E S}$ is the total DC output power from RES. The power balance equation at PCC is given by Eqn. (2).

$P_{m w}=P_{G}+P_{\text {loss }}$

where Pinv is power available at inverter terminals on grid side, PG is total real power supplied and Ploss is total loss in the inverter. The current delivered by the DC link is shown in Eqn. (3).

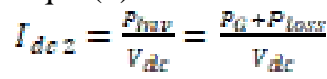

By neglecting the inverter losses, the total power produced by RES and supplied to grid through inverter is expressed by Eqn. (4).

$P_{\text {AES }}=P_{G}$

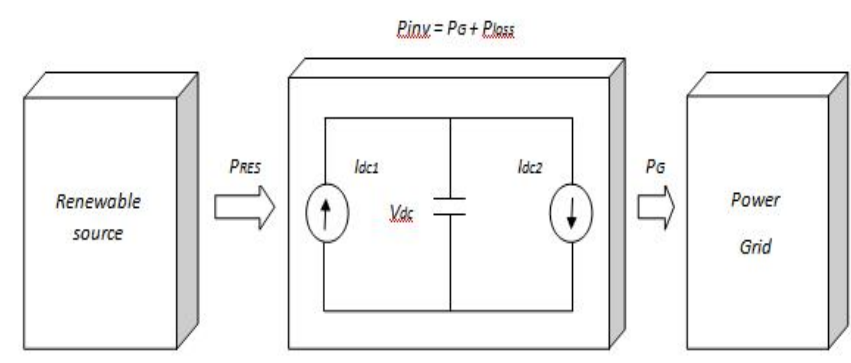

Figure 2: Equivalent diagram of DC-Link

\section{GRID INTEGRATING INVERTER CONTROL}

The proposed controller for integration of inverter to 3-phase with neutral system is depicted in Figure 3. The inverter in this configuration contains four legs each for three phases and neutral. To compensate the load neutral current when the system is unbalanced, the fourth leg is used. The controller is designed in such a way that it regulates the power transfer to the PCC during the following conditions of power availability of RES. (i) $P_{R E S}=0$, (ii) $P_{R E S}<P_{L}$ and (iii) $P_{R E S}>P_{L}$. The term $P_{L}$ denotes the total load power requirement [12],[13],[14]. 
K Lokeswara Rao et al., International Journal of Emerging Trends in Engineering Research, 8(8), August 2020, 4607 - 4612

The controller is designed which deliver active component of power to grid to ensure the power efficient operation and power quality. If load is connected to PCC, any unbalanced or combination of the former occurs, the inverter controller will mitigate harmonics and makes the neutral current balancing. The unbalanced load treated as balanced resistive load by using switching pulses and duty cycle of the inverter [9].

The DC link voltage regulation provides the active power flow between RES and the grid. The component of active current is produced by DC voltage regulator. To ensure grid currents are balanced, the reference value of neutral current $\mathrm{I}_{\mathrm{n}}{ }^{*}$ is usual to zero. Meanwhile, the voltage vector synchronizing angle $\theta$ is provided by the PLL.

To switching ripples in the DC voltage can be eliminated with the inclusion of filter into control circuit, the measured DC link voltage $\mathrm{V}_{\mathrm{dc}}$ is given first-order low pass filter for the former mentioned operation. The PI controller is inserted to attain dynamic / unexpected voltages near the dc-link [10]. The DC link $\mathrm{n}^{\text {th }}$ sampling instant voltage error $\mathrm{V}_{\mathrm{dcerr}(\mathrm{n})}$ and PI regulator output is expressed by Eqns. $(5 \& 6)$ :

$\mathrm{V}_{\mathrm{dcerr}(\mathrm{n})}=\mathrm{V}_{\mathrm{dc}(\mathrm{n})}{ }^{*}-\mathrm{V}_{\mathrm{dc}(\mathrm{n})}$

$I_{m(n)}=I_{m(n-1)}+10\left(V_{\text {dcerr(n) }}-V_{\text {dcerr(n-1) }}\right)+0.05 V_{\text {deerr(n) }}$

The sudden changes in grid currents are obtained by Eqns from (7-9).

$\mathrm{I}_{\mathrm{a}}{ }^{*}=\mathrm{I}_{\mathrm{m}} \cdot \mathrm{U}_{\mathrm{a}}$

$\mathrm{I}_{\mathrm{b}}{ }^{*}=\mathrm{I}_{\mathrm{m}} \cdot \mathrm{U}_{\mathrm{b}}$

$\mathrm{I}_{\mathrm{c}}{ }^{*}=\mathrm{I}_{\mathrm{m}} \cdot \mathrm{U}_{\mathrm{c}}$

Where $\mathrm{I}_{\mathrm{n}}{ }^{*}=0$ because of current balancing. $\mathrm{I}_{\mathrm{a}}{ }^{*}, \mathrm{I}_{\mathrm{b}}{ }^{*}, \mathrm{I}_{\mathrm{c}}{ }^{*}$ are corresponds to reference currents in a, b, c phases.

The reference and actual currents of grid $\left(\mathrm{I}_{\mathrm{a}}, \mathrm{I}_{\mathrm{b}}, \mathrm{I}_{\mathrm{c}} \& \mathrm{I}_{\mathrm{n}}\right)$ are compared to calculate the errors in current with the help of Eqn. (10-13) in order to produce PWM pulses for the inverter [11].

$\mathrm{I}_{\text {aerr }}=\mathrm{I}_{\mathrm{a}}{ }^{*}-\mathrm{I}_{\mathrm{a}}$
$\mathrm{I}_{\text {berr }}=\mathrm{I}_{\mathrm{b}}{ }^{*}-\mathrm{I}_{\mathrm{b}}$
$\mathrm{I}_{\text {cerr }}=\mathrm{I}_{\mathrm{c}}{ }^{{ }^{*}-\mathrm{I}_{\mathrm{c}}}$
$\mathrm{I}_{\text {nerr }}=\mathrm{I}_{\mathrm{n}}{ }^{*}-\mathrm{I}_{\mathrm{n}}$



Figure 3: Control strategy of grid-integrating inverter
The hysteresis current controller is fed by current errors for the inverter PWM pulses generation, to deliver power from RES [11]. The average model of the inverter with neutral connection is given by Eqn. (14) - (18).

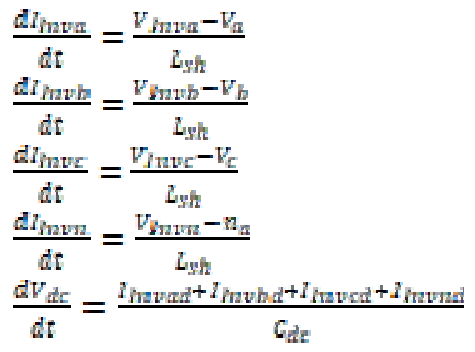

where, $\mathrm{V}_{\text {Inva }}, \mathrm{V}_{\text {Invb }}, \mathrm{V}_{\text {Invc }}, \mathrm{V}_{\text {Invn }}$ and $\mathrm{I}_{\text {Inva }}, \mathrm{I}_{\text {Invb }}, \mathrm{I}_{\text {Invc }}, \mathrm{I}_{\text {Invn }}$ are the voltages and currents at the inverter output terminals a,b,c and neutral. The expressions for terminal voltage are as shown Eqn. (19) - (22).

$V_{\operatorname{ma}}=\frac{\mathbb{P}_{1}-P_{4}}{2} V_{d c}$

$V_{\text {lww }}=\frac{P_{3}-P_{i c}}{2} V_{d c}$

$V_{\text {wwe }}=\frac{p_{x}^{2}-p_{2}}{2} V_{d c}$

$V_{m w}=\frac{p_{z}^{2}-p_{11}}{2} V_{d e}$

Similarly, the charging currents ( $\left.\mathrm{I}_{\text {Invad }}, \mathrm{I}_{\text {Invbd }}, \mathrm{I}_{\text {Invcd, }} \mathrm{I}_{\text {Invndon }}\right)$ in terms of inverter phase currents and switching pulses are given by Eqn. (23) - (26).

$I_{\text {lnuad }}=I_{\text {mua }}\left(P_{1}-P_{4}\right)$

$I_{\text {lawd }}=I_{\text {hwo }}\left(P_{1}-P_{6}\right)$

$I_{\text {lnod }}=I_{\text {lwwe }}\left(R_{5}-P_{2}\right)$

$I_{\text {lnund }}=I_{\text {mun }}\left(P_{7}-P_{n}\right)$

The sequence of switching inside IGBT inverter has done on the bases of deviation of current from its actual value. The possible conditions depending on the value of error are as follows:

1. If $\mathrm{I}_{\text {Inva }}<\left(\mathrm{I}_{\text {Inva }}{ }^{*}-\mathrm{h}_{\mathrm{b}}\right)$, then $\mathrm{P}_{1}=0$ pulse for $\mathrm{S}_{1}$ is disconnected and $\mathrm{S}_{4}$ will be active $\left(\mathrm{P}_{4}=1\right)$.

2. If $\mathrm{I}_{\text {Inva }}>\left(\mathrm{I}_{\text {Inva }}{ }^{*}-\mathrm{h}_{\mathrm{b}}\right)$, then $\mathrm{P}_{1}=1$ pulse for $\mathrm{S}_{1}$ is in active and vice versa for $\mathrm{S}_{4}$.

where the hysteresis band width of hysteresis controller is denoted by $h_{b}$.

\section{THE MATLAB/SIMULINK MODEL OF THE GRID INTERCONNECTED RES}

The performance evaluation of the propose system with 3-phase 4-wire configuration with various objectives is evaluated by using MATLAB/Simulink. Figure 4 shows control scheme with conventional PI-controller the current controlled VSI with the proposed controller maintaining Unity Power Factor and balancing the neutral current there by improving the performance of the system when operating with nonlinear unbalanced loading at PCC. Figure 5 shows the usage of DC link that improves the active power deliver to grid though the source of energy is intermittent in nature. Figure 6 shows the proposed controller actively, mitigating 
harmonics caused by nonlinear loads, reactive power compensation at PCC. The grid voltages $\left(\mathrm{V}_{\mathrm{a}}, \mathrm{V}_{\mathrm{b}}, \mathrm{V}_{\mathrm{c}}\right)$ and currents $\left(I_{a}, I_{b}, I_{c}\right)$ with non-linear loads when RES is not connected to grid.

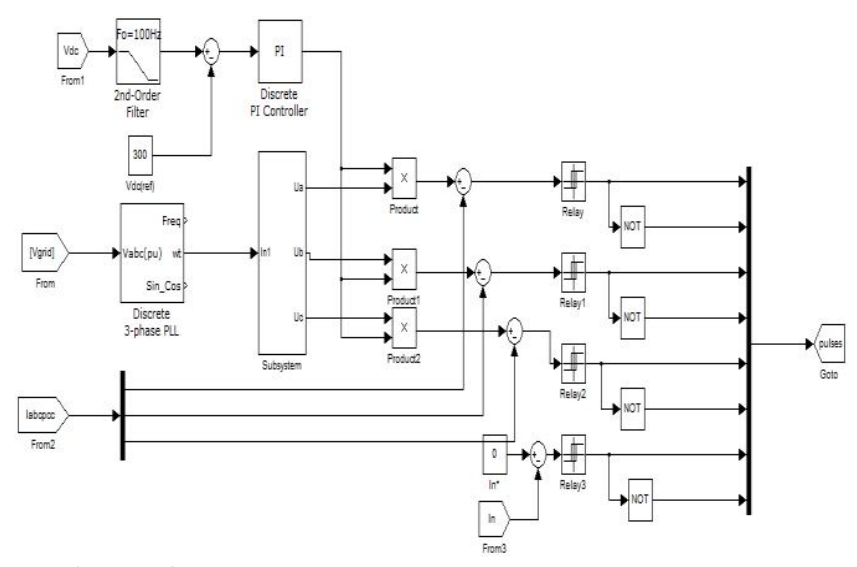

Figure 4: Proposed control scheme with conventional PI-controller

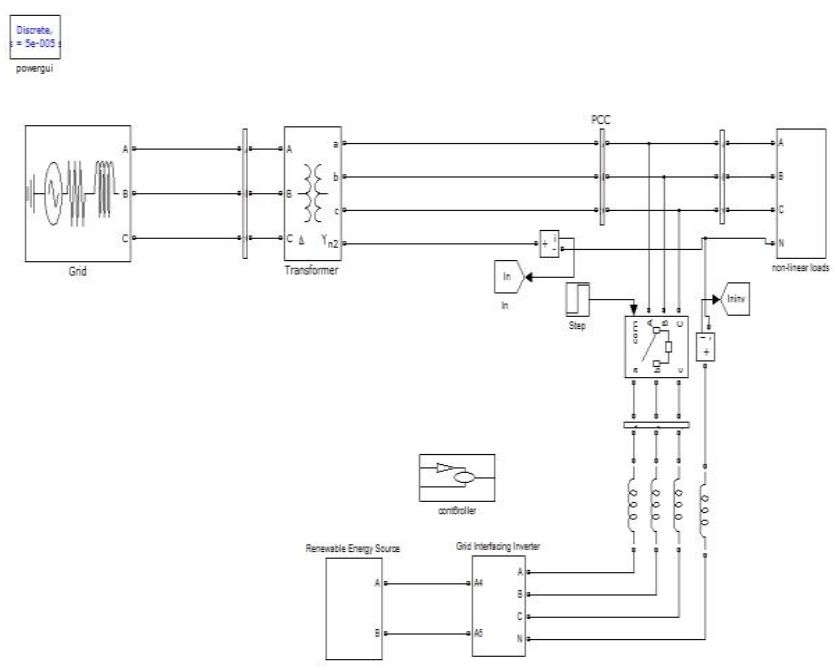

Figure 5: Proposed system with grid interconnection
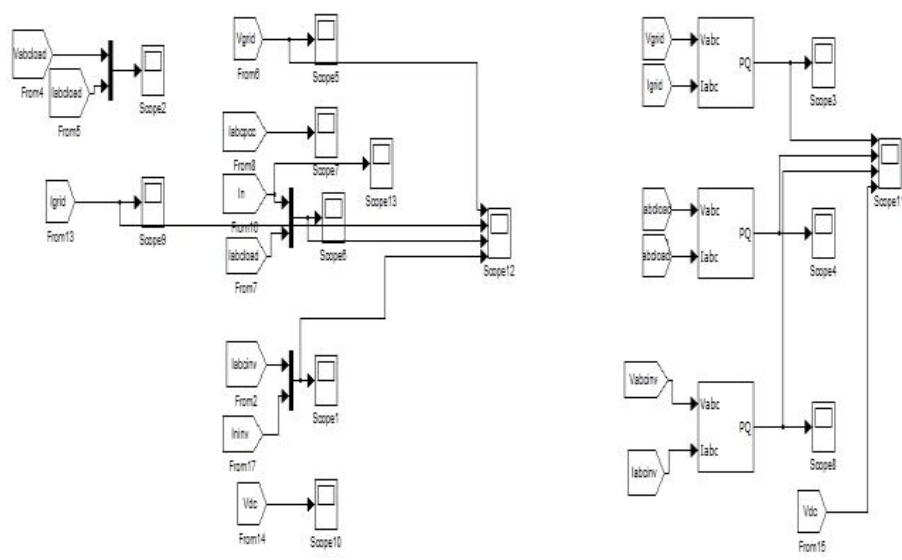

Figure 6: Developed system model in Simulink to measure grid, load, inverter voltages, currents, active and reactive powers.

\section{SIMULATION RESULTS}

Figure 7 shows Voltage $\mathrm{V}_{\mathrm{abc}}$, Currents $\mathrm{I}_{\mathrm{abc}}$ waveforms of grid, dynamic load $\left(\mathrm{I}_{\mathrm{labc}}\right)$ and inverter currents $\left(\mathrm{I}_{\mathrm{invabc}}\right)$.

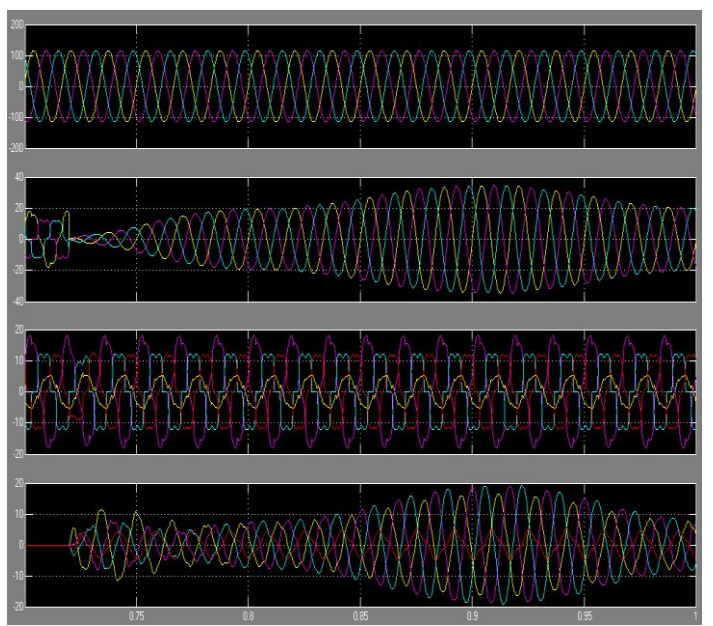

Figure 7: Voltages \& currents of the grid, dynamic load and Inverter currents.

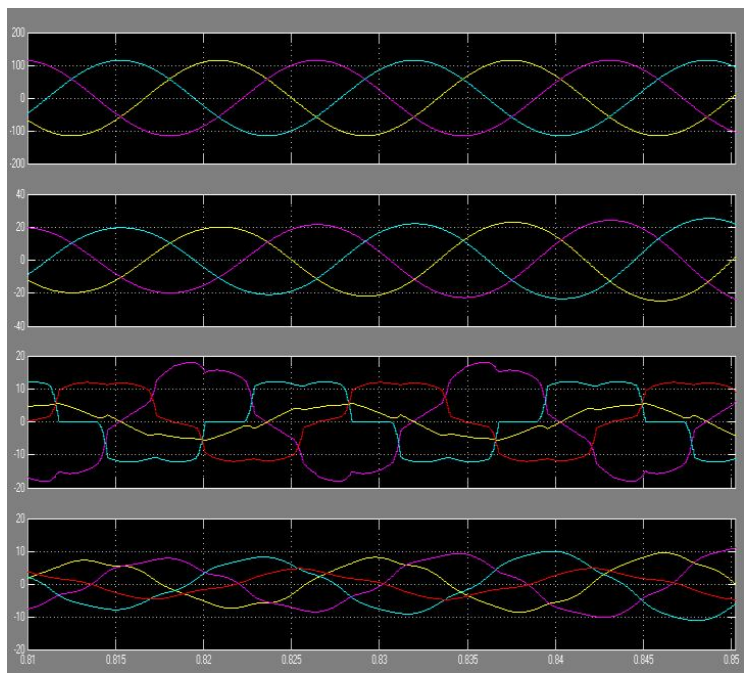

Figure 8: Grid real \& reactive powers, load and inverter

Figure 8, shown the grid active and reactive powers, load and inverters. The rise in waveform of powers indicates the power flow from grid and inverter to PCC. The +ve sign directs the real and reactive power disbursed by the load. Initially, the total load supply demand is zero because the grid-interfacing inverters will not be interfaced to the system. So, up to $t=0.72$ $\mathrm{s}$, the grid supplies the load demand which indicates that, grid current is equal to load current. From $t=0.72 \mathrm{~s}$, the inverter interfaces the network and grid which results in inverter starts injecting current to the grid. Subsequently the grid current profile changes to a balanced sinusoidal current from unbalanced nonlinear current.

The direction of active and reactive power flows to grid, load, inverter and DC-link voltage at $\mathrm{t}=0.72 \mathrm{~s}$ are shown in Figure 9. From $t=0.72 \mathrm{~s}$, the inverter begin to supplying active power 
to grid. If the RES produced power is higher than demand of load, the surplus amount will be supplies to grid which can be observed after $\mathrm{t}=0.72 \mathrm{~s}$ (negative sign of $\mathrm{P}_{\text {grid }}$ ).



Figure 9: Real and reactive power flows to the grid, load and inverter along with dc-link voltage

Therefore, after inverter interfacing the grid and network, the grid either can supplies/receives the real power depending on the load demand. From, $\mathrm{t}=0.82 \mathrm{~s}$, the real power generation is improved for performance evaluation of the inverter control scheme under variable RES conditions which results in increased inverter current. At this instant, if the load demand is constant, excess RES power generated will be supplied to the grid, it is noticed at enhanced inverter current. From $\mathrm{t}=0.92 \mathrm{~s}$, the power generated from RES is decreased, which results in corresponding change in inverter \& grid current and real, reactive power from inverter to load as well in grid. Moreover, the DC-link voltage needs to be maintained constant in any operating condition for smooth power flow.

\section{CONCLUSION}

In this paper, a 3-phase 4-wire DS is presented. The grid interfacing inverter control is implemented and tested at various load conditions. The controller enables the injection of power in to the grid with maximum utilization of the RES included in the system. The simulation results shown that, grid-interfacing VSI is efficiently operated as power controlling equipment without affecting the transfer of active power. The control scheme of VSI is implemented to transfer the active power flow to grid and to operate as shunt APF. The integrated inverter suppressing, all the harmonics and neutral currents injected by the non-linear loads efficiently. To enhance the power quality, this control scheme doesn't require the auxiliary power conditioning equipment. Further improvements in the work will be carried out by adding AI to the system for the better understanding of faults occurred on the system.

\section{REFERENCES}

1. J. M. Guerrero, L. G. de Vicuna, J. Matas, M. Castilla, and J. Miret,A wireless controller to enhance dynamic performance of parallel inverters in distributed generation systems, IEEE Trans. Power Electron.,vol. 19, no. 5, pp. 1205-1213, Sep. 2004.

2. J. H. R. Enslin and P. J. M. Heskes, Harmonic interaction between a large number of distributed power inverters and the distribution network, IEEE Trans. Power Electron., vol. 19, no. 6, pp. 1586-1593, Nov. 2004. https://doi.org/10.1109/TPEL.2004.836615

3. U. Borup, F. Blaabjerg, and P. N. Enjeti, Sharing of nonlinear load in parallel-connected three-phase converters, IEEE Trans. Ind. Appl. vol. 37, no. 6, pp. 1817-1823, Nov./Dec. 2001.

4. P. Jintakosonwit, H. Fujita, H. Akagi, and S. Ogasawara, Implementation and performance of cooperative control of shunt active filters for harmonic damping throughout a power distribution system, IEEE Trans. Ind. Appl., vol. 39, no. 2, pp. 556-564, Mar./Apr. 2003.

5. S. Chaithanya, V.N.B Reddy, R Kiranmayi, A Narrative Review on Offshore Wind Power Transmission using Low Frequency Transmission System, In Proceedings of IEEE Smart Tech for Smart Nation, Bangalore, India, pp. 397-403, 2017.

6. F. Blaabjerg, R. Teodorescu, M. Liserre, and A. V. Timbus, Overview of control and grid synchronization for distributed power generation systems, IEEE Trans. Ind. Electron., vol. 53, no. 5, pp. 1398-1409, Oct. 2006. https://doi.org/10.1109/TIE.2006.881997

7. J. M. Carrasco, L. G. Franquelo, J. T. Bialasiewicz, E. Galván, R. C.P. Guisado, M. Á. M. Prats, J. I. León, and N. M. Alfonso, Power electronicsystems for the grid integration of renewable energy sources:A survey, IEEE Trans. Ind. Electron., vol. 53, no. 4, pp. 1002-1016, Aug. 2006.

8. B. Renders, K. De Gusseme, W. R. Ryckaert, K. Stockman, L. Vandevelde, and M. H. J. Bollen, Distributed generation for mitigating voltage dips in low-voltage distribution grids, IEEE Trans. Power.Del., vol. 23, no. 3, pp. 1581-1588, Jul. 2008.

9. Seetha Chaithanya, V. Naga Bhaskar Reddy and R. Kiranmayi, Modeling \& Analysis of Grid Tied PMA based Offshore Wind Energy System using PSCAD/EMTDC, Ain Shams Engineering Journal, Vol. 10, pp. 411-417, 2019.

10. J. P. Pinto, R. Pregitzer, L. F. C. Monteiro, and J. L. Afonso, 3-phase4-wire shunt active power filter with renewable energy interface, presented at the Conf. IEEE Renewable Energy \& Power Quality, Seville, Spain, 2007.

11. V. Khadkikar, A. Chandra, A. O. Barry, and T. D. Nguyen, Application of UPQC to protect a sensitive 
K Lokeswara Rao et al., International Journal of Emerging Trends in Engineering Research, 8(8), August 2020, 4607 - 4612

load on a polluted distribution network, in Proc. Annu. Conf. IEEE Power Eng. Soc. Gen. Meeting, 2006, pp. 867-872.

12. Ramprasad Vangalapudi, Dr. K.Ravikanth Wind Power Influence on the Small Signal Stability of Grid Integrated Distribution Systems, International Journal of Emerging Trends in Engineering Research, July 2020 https://doi.org/10.30534/ijeter/2020/112872020.

13. Jahnavi1Koganti Srilakshmi P. Ravi Babu P. Aravindhababu Unified Power Quality Conditionerfor Power Quality Enhancement of Distribution System Using Space Vector Pulse Width Modulation Based Fuzzy Controller International Journal of Emerging Trends in Engineering Research June 2020.

14. K Chaitanya , Dr. K Rajasekhra Rao , Dr. JKR Sastry A Formal and Enriched Framework for Testing Distributed Embedded Systems International Journal of Emerging Trends in Engineering Research, December 2019. 